The same investigators have now carried the story a stage further by observing the effect of the vaccines on children in families and classroom groups. ${ }^{7}$. Altogether 1,337 children, whose ages ranged from 1 to 11 years (average 3.6 years) were included in the study. Of these, 482 had a negative history of mumps and 362 were found to be without antibody. Thus the patients' negative history given by the parents was accurate in $75 \%$ of cases. Three hundred and fifty-nine of the 362 susceptible children developed an immune response after inoculation of $1 \mathrm{ml}$. of the freezedried vaccine-a sero-conversion rate of $98 \%$. None of the 500 uninoculated control children in contact with the vaccinated children in the family or classroom groups showed evidence of mumps or developed mumps antibody. No excess of reactions was noted between the inoculated groups and the controls, and no interference with the response to mumps vaccine was detected in children who were also administered a killed polyvalent respiratory virus vaccine. The antibody levels after the mumps vaccine were considerably lower than those usually encountered after natural mumps. Nevertheless, from the experience with attenuated measles vaccine this is to be expected, and the low levels may still be protective. It was found that the serum neutralization test was more specific and sensitive for detecting low levels of antibody than was the haemagglutinationinhibition test. ${ }^{7}$

Soon after these studies had been completed a chance arose to evaluate the protective effect of the vaccine. ${ }^{9}$ Mumps, which had been endemic at the time of the first trial, became epidemic a few months later. One hundred vaccinated and 100 unvaccinated children at risk to natural mumps were observed. The overall attack-rate among the control group was $61 \%$, in contrast to $2 \%$ in the vaccinated children, the protective effect being $97 \%$. If the clinically diagnosed cases are included with the virologically proved cases of mumps in the families and classrooms, the overall protective effect was $98 \%$.

Experience with live mumps vaccine in the Soviet Union extends over several years. More than one million children have now received a lyophilized vaccine also prepared in chick embryo fibroblasts. The reduction in morbidity has

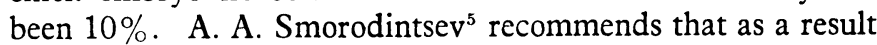
of waning immunity revaccination would be necessary after four to five years.

These reports are encouraging, but it is too early to say how long protection from such a vaccine will last. From the analogy with measles vaccine-and there are many points of similarity between these two vaccines not only in the method of their development but in the immune responses they evoke-there is every hope that immunity will be of long duration. If not, it can be reinforced by further immunization.

What is the need for a mumps vaccine? This is a more difficult question to answer. In the past few years amazing

1 Kabat, E. A., New Engl. F. Med., 1963, 269, 247.

2 Cabasso, V. J., in Report on 1st International Conference on Vaccines against Viral and Rickettsial Diseases in Man, p. 417. Pan American against Viral and Rickettsial Diseases No. 147.1967.

Ibid., 1967.

- Weibel, R. E., et al., ibid., 1967, p. 430.

5 Smorodintsev, A. A., et al., ibid., 1967, p. 422.

Stokes, J., Weibel, R. E., Buynak, E. B., and Hilleman, M. R. Pediatrics, 1967, 39, 363.

Weibel, R. E., Stokes, J., Buynak, E. B., Whitman, J. E., and Hilleman, M. R., New Engl. f. Med., 1967, 276, 245.

- U.S. Department of Health, Additional Standards : Regulations, Live Attenuated Measles Virus Vaccine. Government Printing Office, Washington, D.C. Title 42, Part 73, page 34. 1965.

"Hilleman, M. R., Weibel, R. E., Buynak, E. B., Stokes, J., and Whitman, J. E., New Engl. f. Med., 1967, 276, 252. progress has been made in the development of viral vaccines, and before long nearly all the common infectious diseases will be preventable by immunization. Measles vaccine is already being widely used in the United States, and the incidence of the disease there is the lowest on record for many years. Preliminary data indicate that mumps vaccine appears to be safe and protective, and there are good prospects that a vaccine against rubella will be developed in due course. Each disease presents its own special problems, and the development of a safe and effective vaccine must be considered in relation to the need for a vaccine, the age of immunization, and the extent to which this should be carried out, and more especially the safety of a vaccine in relation to the cell substrate in which the virus is propagated. In this connexion the choice of chick embryo tissue as the source for the mumps vaccine would appear to be a distinct advantage in view of the knowledge already gained about the safety of such vaccines from experience with live measles vaccine.

Mumps is a relatively benign disease in children, but it is a considerable nuisance, particularly from time lost at school. The importance of complications is more difficult to assess. Infections of the central nervous system occur in mumps more often than in any other infectious disease, but rarely are they serious. Cranial nerve palsies, transverse myelitis, and occasionally death from demyelinating encephalitis have been reported, but these are rare. The commonest neurological complication is aseptic meningitis, which carries a good prognosis. Deafness also follows mumps; it is uncommon but can be severe. Orchitis is a common complication and is supposed to lead to sterility, but the risks of this are not great because most cases of mumps orchitis are unilateral. Other complications such as pancreatitis followed by diabetes and myocarditis have been reported, but they too are rare in relation to the frequency of mumps infection. The only method of preventing complications in either children or adults is by immunization, preferably carried out in childhood. The preliminary results are distinctly encouraging, but there is no obvious need immediately for mass immunization with a view to eradication of the disease. It will be necessary to feel our way with further studies on duration of immunity. A mumps vaccine might be useful for groups of people at special risk such as in the armed Forces and in an outbrcak. A further interesting development in this field comes in a report from the U.S.S.R. ${ }^{5}$ of preliminary results of a combined attenuated vaccine against measles and mumps.

\section{Isoniazid and Cancer}

Isoniazid, first used clinically in 1951, has proved a major therapeutic success. It is generally regarded as the most active and least toxic of the antituberculosis drugs. It is also cheap. Its usefulness in the control of what is still a formidable killing disease in many parts of the world is unsurpassed. But just because the drug is so exceptionally effective and so widely used it is specially important to evaluate laboratory reports which seem to cast doubt on its safety. Many investigators have shown that oral or parenteral administration of isoniazid results in the appearance of tumours of the lung, predominantly adenomas, in certain strains of mice. ${ }^{1}$ While results in other strains of mice and in other animals have been negative, ${ }^{2}$ the evidence that the drug can induce lung tumours in mice appears conclusive. It poses the question of how far, if at all, this finding is relevant to the use of 
isoniazid in man. ${ }^{3-5}$ Clearly the answer can come only from human experience, and the epidemiological studies by E. C. Hammond, I. J. Selikoff, and E. H. Robitzek reported in this week's B.M.f. (p. 792) allow a more direct assessment of the risk than has hitherto been possible.

Hammond and his colleagues have investigated cancer death rates in four groups of subjects. In one, patients with tuberculosis initially treated with isoniazid between 1951 and 1956 were followed up to June 1966 . Among 56 who died during the 10 - to 15 -year period there were eight confirmed cancers and a further two deaths in which malignant disease was suspected but not firmly proved. Including the latter, the total of 10 cancer deaths was not significantly different fror: the number expected (6.3) on general population experience. Separate consideration of male cancer deaths, however, did show a more marked difference between observed (nine deaths) and expected (four deaths) mortality. These numbers are too small to be more than slightly suggestive, and the absence of any dose-response relationship or time relationship (to start of isoniazid therapy) supports the authors' view that the findings in male patients were essentially negative. Findings in female patients were completely negative, with only one "doubtful " cancer death compared with the estimated two or three deaths expected. Evidence from two other studies was also negative. In the first, 502 women treated with isoniazid during pregnancy were followed up for periods up to 13 years after their " isoniazid pregnancy." None died of cancer during this time. Follow-up of the children resulting from these pregnancies was equally reassuring. All were alive and, as far as is known, none had cancer or any malady suggestive of cancer. In their fourth investigation Hammond and his colleagues examined the experience of more than 18,000 adults who on enrolment in 1959 in an American Cancer Society prospective study gave a history of previous tuberculosis. Followed up over the next five years, this tuberculous group, only a small minority of whom may have had isoniazid, had a lung cancer mortality slightly higher than that of persons without a previous history of tuberculosis. While the data are too few to confirm that the difference is real, they leave open the possibility that tuberculosis per se may slightly increase the risk of lung cancer.

Epidemiological study of possible long-term risks of isoniazid has to be based almost entirely on the experience of tuberculous patients, and it is complicated by both the relatively short time since the introduction of isoniazid therapy and the selective nature of the population treated. ${ }^{6}$ Up till now there has been little or no solid evidence upon which to assess the risks, so the present data are welcomeeven if they do not provide a conclusive answer as to whether or not isoniazid is carcinogenic in man. Taken as a whole, the studies are reassuring in their failure to demonstrate any convincing evidence of increased cancer risk among men, women, and children observed for periods up to 15 years. But clearly further epidemiological studies are needed. It is encouraging to note that these are already under way ${ }^{6} 7$ and that at least one study population of 70,000 persons, admitted to controlled trials designed to test the prophylactic effect of isoniazid, forms a particularly appropriate group for

\footnotetext{
1 Biancifiori, C., and Severi, L., Brit. F. Cancer, 1966, 20, 528.

Peacock, A., and Peacock, P. R., ibid., 1966, 20, 307.

Roe, F. J. C., Boyland, E., and Haddow, A., Brit. med. F., 1965, 1, 1550

- Ibid., 1965, 1, 1508.

- Lancet, 1966, 2, 1452

- Ferebee, S. H., Brit. med. 7., 1965, 2, 1122.

Fox, W.. Lancet, 1967, 1, 221
}

long-term surveillance. The ultimate experience of this group should prove decisive, but results of the study may not be known for some years. Until a conclusive answer is reached, there will remain a useful place for smaller but carefully planned investigations to confirm and extend the preliminary but on the whole reassuring findings of Hammond and his colleagues.

\section{Future of Mental Hospitals}

In his Hospital Plan published in 1962 the then Minister of Health, Mr. Enoch Powell, predicted the change of use of half the mental hospitals in ten years and the splitting of their function between community agencies and general hospitals. Much of the ammunition he used came from the studies of Dr. G. C. Tooth and Miss E. M. Brooke. ${ }^{1}$ The battle of the medical statisticians was on, but so far its outcome is undecided.

Now Miss Brooke, from the Ministry of Health's statistical High Command, has produced $A$ Census of Patients in Psychiatric Beds, 1963. Entering the lists on her behalf, Sir George Godber in his introduction writes : "The most important conclusion is that the reduction in need for hospital beds forecast by Miss Brooke and Dr. Tooth in 1961 is occurring." The introduction is not dated, but the fact remains that since 1963 a formidable volume of evidence has suggested the contrary. For example, R. V. Magnus ${ }^{3}$ in a paper significantly entitled "The New Chronics" states that in his hospital in Bristol "chronics" are accumulating. Again, J. A. Baldwin and D. J. Hall ${ }^{4}$ in a statistically sophisticated and persuasive paper based on data from north-east Scotland showed that, though the time which would elapse for the population of a given mental hospital to be halved may be fairly short, the time required for complete elimination would be over fifty years.

These two papers among others pinpoint the fallacy of attempting to legislate for the country as a whole when regional variations may be wide. Indeed, this is exactly the theme which recurs constantly in Miss Brooke's own publication. For example, the range of beds available per 1,000 population varied from 2.1 in the Oxferd Region to 5.8 in the South-west Metropolitan Region, where, even so, overcrowding still exists. The percentage bed occupancy over all regional board hospitals was 92, and ranged in individual regions from $80 \%$ in the Oxford region to $96 \%$ in Liverpool.

Sir George Godber also states that between 1954 and 1963 mentally ill patients decreased by 20,000 . We are entitled to ask how much this reduction in the population of mental hospitals is the result of restoration to health through therapeutic advances and how much is a sociological conjuring trick. What is the state of these discharged patients ? How many are represented among the record number of 9,555 offenders remanded in custody in 1965 for medical reports,

\footnotetext{
1 Tooth, G. C., and Brooke, E. M., Lancet, 1961, 1, 710.

Brooke, E. M., A Census of Patients in Psychiatric Beds, 1963. Ministry of Health, Reports on Public Health and Medical Subjects No. 116. 1967. H.M.S.O.

s Magnus, R. V., Brit. f. Psychiat., 1967, 113, 555.

- Baldwin, J. A., and Hall, D. J., Brit. 7 . prev. soc. Med., 1967, 21, 56

- Homeless Single Persons, Ministry of Pensions and National Insurance. omeless Single Person
1966. H.M.S.O.

- Brit. med. F., 1966, 2, 1546.

Scott, R., Gaskell, P. G., and Morrell, D. C., ibid., 1966, 2, 1561.

- Berry, C., and Orwin, A., Brit. F. Psychiat., 1966, 112, 1019.

- Ministry of Health, For the Mentally Ill.'A Survey of Thirty-one Hostels. 1966. London.
} 